\title{
Prosedur Clearance In Dan Clearance Out Kapal Milik PT. Salam Pacific Indonesia Lines
}

\author{
Bellin Fattah Auliya ${ }^{1}$, Iswanto ${ }^{2 *}$, Ningrum Astriawati ${ }^{3}$, Handoyo Widyanto ${ }^{4}$ \\ ${ }^{1}$ Alumni Prodi MTL, Sekolah Tinggi Maritim Yogyakarta, Jl. Magelang KM 4.4, \\ Yogyakarta 55284, Indonesia \\ ${ }^{2,3,4}$ Sekolah Tinggi Maritim Yogyakarta, Jl. Magelang KM 4.4, Yogyakarta 55284, \\ Indonesia \\ * Corresponding Author. E-mail : isnogotirto59@gmail.com. Telp : +62 812-2741-634
}

\begin{abstract}
Abstrak
Tujuan dari penelitian ini adalah untuk mengetahui prosedur clearance in dan clearance out kapal milik PT. Salam Pacific Indonesia Lines di Pelabuhan Tanjung Priok. Penelitian ini menggunakan metode pendekatan deskriptif kualitatif. Metode pengumpulan data terbagi menjadi 4 bagian yaitu: metode observasi secara langsung di lapangan,) metode interview atau wawancara dengan kepala cabang beserta staf atau karyawan PT. Salam Pacific Indonesia Lines (SPIL) Cabang Jakarta, metode documenter terkait dengan dokumen yang diperlukan pada saat proses clearance in dan clearance out kapal, metode studi pustaka yang berhubungan dengan prosedur clearance in dan clearance out kapal. Dari hasil penelitian disimpulkan bahwa di dalam kegiatan clearance in dan clearance out kapal pihak dinas luar PT. Salam Pacific Indonesia Lines diharuskan melakukan kegiatan tepat dan cepat. Prosedur sudah dilakukan dengan baik. Semua kegiatan sudah terorganisir untuk mengurangi kesalahan saat melakukan kegiatan clearance in dan clearance out kapal tersebut.
\end{abstract}

Kata Kunci: Prosedur, Clearance In, Clearance Out

\begin{abstract}
The purpose of this study was to determine the procedures for permits in and out of ships belonging to PT. Greetings Pacific Indonesia Lines at Tanjung Priok Port. This study uses a qualitative descriptive approach. Data collection methods are divided into 4 parts, namely: direct observation in the field,) interviews or interviews with branch heads and staff or employees of PT. Greetings Pacific Indonesia Lines (SPIL) Jakarta Branch, the documentary method is related to the documents required during the clearance in and out of the ship, the literature study method related to the procedures for clearance in and out of the ship. From the results of Key's research that in the activities of clearance in and clearance out of ships, the outside service PT. Salam Pacific Indonesia Lines is required to carry out activities correctly and quickly. The procedure has been done well. All activities have been organized to reduce errors when carrying out clearance in and out of the ship.
\end{abstract}

Keywords: Procedure, Clearance In, Clearance Out 


\section{PENDAHULUAN}

Indonesia adalah negara kepulauan terbesar didunia, negara kepulauan ini artinya negara yang terdiri dari banyak pulau yang dihubungkan dengan laut yang luas yang menjadi bagian dominan atas daratan baik besar maupun kecil. Logikanya, laut menjadi pilihan untuk melakukan kegiatan penghubungan antara pulau-pulau yang ada tersebut, sebagai aktifitas kegiatan pengangkutan barang maupun manusia. Seiring berjalannya waktu maka kebutuhan transportasi antar pulau di Indonesia semakin banyak dan meningkat tiap tahunnya. Sehubungan dengan itu dibuatlah berbagai macam inovasi untuk meningkatkan kegiatan pengiriman barang kesetiap pulau untuk memenuhi kebutuhan tersebut. Dengan adanya kegiatan pengangkutan sangat membantu orang-orang untuk saling terhubungan satu dengan yang lainnya(Samekto \& Soejanto, 2014).

Dalam Undang-Undang Republik Indonesia No. 17 Tahun 2008 Tentang Pelayaran menyebutkan bahwa pelayaran adalah satu kesatuan sistem yang terdiri dari atas angkutan dan perairan, kepelabuhanan, keselamatan dan keamanan, serta perlindungan maritim. Kegiatan pelayaran pada umumnya adalah mengangkut muatan dan penumpang dari pelabuhan pemuatan ke pelabuhan tujuan. Untuk itu perusahaan pelayaran saling mengeluarkan inovasi-inovasi baru untuk mempercepat, mempermudah kegiatan dalam pengiriman barang maupun penumpang dengan sarana-prasarana yang memadai dalam melakukan kegiatan tersebut.

Dalam melaksanakan kegiatannya perusahaan pelayaran berusaha menekan biaya yang sekecil mungkin yang dikeluarkan terutama selama di pelabuhan(Wijaya et al., 2020). Perusahaan pelayaran harus berupaya memberikan pelayanan yang terbaik bagi pengguna jasa(Pattiasina \& Ningrat, 2021). Salah satu kegiatan yang disediakan oleh perusahaan pelayaran adalah agent, untuk mengatasi permasalahan kapal yang menunggu untuk kegiatan bongkar muat, labuh, tambat, pengisian BBM, dan membantu pihak pemilik dalam mengurusi kapal maupun awaknya selama di pelabuhan, karena tidak semua perusahaan pelayaran mempunyai cabang di semua Pelabuhan(Sugeng \& Palippui, 2021).

Untuk memperlancar arus keluar masuk kapal maka segala keperluan kapal akan diurus agen perusahaan pelayaran baik dalam mengurusi keperluan menjelang kedatangan kapal, selama kapal di pelabuhan sampai kapal meninggalkan pelabuhan. Karena jika arus keluar masuk kapal mengalami keterlambatan (delay) maka perusahaan akan mengalami kerugian(Anita \& Asmadewa, 2017). Adapun tugas agen ada dua yaitu pelayanan kapal (ship's husbanding) dan operasi keagenan (cargo operation). Tugas-tugas yang termasuk dalam pelayanan kapal adalah pelayanan Anak Buah Kapal (ABK), perbaikan atau pemeliharaan kapal, penyediaan onderdil atau suku cadang kapal, dan sebagainya. Sedangkan tugas yang berkaitan dengan operasi keagenan adalah pengurusan bongkar dan muat, stowage, lashing dan dokumen muatan (Iswanto \& Widyanto, 2019)

Peranan perusahaan pelayaran sangat penting bagi dunia pelayaran di indonesia. PT. Salam Pacific Indonesia Lines (SPIL) mengawali usahanya pada tahun 1984 dengan bergerak di bidang pengiriman barang antar pulau (domestik). Sekitar pada tahun 1996 mengembangkan usaha dari angkutan breakbulk cargo

Majalah Ilmiah Bahari Jogja 88 | http://jurnal.stimaryo.ac.id/index.php/MIBJ/ 
menjadi angkutan yang lebih efisien dengan menggunakan container dan sampai saat ini pun PT. Salam Pacific Indonesia Lines (SPIL) memiliki fasilitas armada kapal sendiri yang telah di lengkapi dengan sertifikasi BKI yaitu ISM code dan ISPS code sebagai bentuk komitmen kecepatan pengiriman barang(Suryantoro et al., 2020).

PT. Salam Pacific Indonesia Lines (SPIL) berpusat di kota Surabaya dan memiliki 18 cabang dan 4 kantor perwakilan tersebar di seluruh wilayah Indonesia, dan salah satu di antar cabang tersebut adalah di Jakarta, yang beralamatkan di JL. Enggano No.90, Tanjung Priok, Jakarta Utara 14310 DKI JAKARTA. PT. Salam Pacific Indonesia Lines cabang Jakarta memiliki 6 lapangan penumpukan Container.Beberapa kantor cabang yang tersebar luas di nusantara yang dimiliki oleh PT. Salam Pacific Indonesia Lines tersebut antara lainnya adalah Aceh, Belawan, Bengkulu, Palembang, Jakarta, Perawang, Batam, Pontianak, Banjarmasin, Balikpapan, Nunukan, Samarinda, Bitung, Sorong, Makassar, Gorontalo, Maluku, Bau-bau, Fak-fak, Ternate, Jayapura dan Merauke. Dari sekian banyak kantor cabang yang dimiliki oleh PT. Salam Pacific Indoensia Lines (SPIL), akan semakin banyak membantu untuk pengiriman barang-barang logistik keseluruh pelosok-pelosok nusantara.

PT. Salam Pacific Indonesia Lines Cabang Jakarta adalah perusahaan pelayaran yang menyediakan jasa keagenan kapal sebagai cabang, agen/sub agen yang bertugas untuk mengurus dokumen Clearance In dan Clearance Out kapal yang akan masuk dan keluar Pelabuhan Tanjung Priok(Renindya, 2020). Setiap kapal yang berlayar wajib memiliki Port Clearance yang di keluarkan oleh Syahbandar setelah kapal memenuhi persyaratan kelaiklautan kapal dan kewajiban lainnya. Suatu perusahaan pelayaran mengoperasikan kapal-kapalnya dari pelabuhan satu ke pelabuhan lainnya. Sehingga perusahaan pelayaran harus mengurusi kapal yang dioperasikan pada saat di pelabuhan yang disinggahinya. Kegiatan pengurusan dokumen untuk proses Clearance In dan Clearance Out kapal yang akan masuk dan keluar pelabuhan pada pihak atau instansi terkait(Dirhamsyah, 2021). Kegiatan Clearance In dan Clearance Out apabila tidak berjalan dengan baik, maka akan menghambat kelancaran penanganan kapal pada saat di pelabuhan yang dilakukan oleh PT. Salam Pacific Indonesia Lines Cabang Jakarta. Oleh karena itu prosedur dokumen Clearance In dan Clearance Out kapal yang akan masuk dan keluar pelabuhan yang baik akan sangat menunjang mutu pelayanan kapal. Karena pentingnya keagenan didalam dunia pelayaran maka peneliti melakukan kegiatan pengumpulan data, observasi, wawancara, mengambil dokumen, meneliti prosedur Clearance In dan Clearance Out Kapal Milik PT. Salam Pacific Indonesia Lines di Pelabuhan Tanjung Priok.

\section{METODE PENELITIAN}

Penelitian ini dilaksanakan di Kantor PT. Salam Pacific Indonesia Lines (SPIL) cabang Jakarta di Pelabuhan Tanjung Priok. Penelitian ini menggunakan metode pendekatan deskriptif kualitatif. Penelitian deskriptif yaitu mengumpulkan data berdasarkan faktor- faktor yang menjadi pendukung terhadap objek penelitian, kemudian menganalisa faktor-faktor tersebut untuk dicari peranannya(Soendari,

Majalah Ilmiah Bahari Jogja | 89 | http://jurnal.stimaryo.ac.id/index.php/MIBJ/ 
2012). Ivanovich Agusta dalam Wibowo et al (2021) menjelaskan bahwa metode pendekatan deskriptif kualitatif adalah metode pengolahan data dengan cara menganalisa faktor-faktor yang berkaitan dengan objek penelitian dengan penyajian data secara lebih mendalam terhadap objek penelitian. Objek penelitian ini adalah PT. Salam Pacific Indonesia Lines (SPIL) Cabang Jakarta.

Jenis dan sumber data terbagi menjadi data primer dan data sekunder(Arikunto, 2010). Data primer adalah data yang diperoleh langsung oleh pengumpul data dari objek penelitiannya. Peneliti mengambil data PT. Salam Pacific Indonesia Lines (SPIL) cabang Jakarta. Data primer pada penelitian ini diperoleh dari hasil wawancara petugas operasional perusahaan pelayaran yang ada diperusahaan tentang proses pengurusan kapal khususnya Clearance In dan Clearance Out milik PT. Salam Pacific Indonesia Lines. Data sekunder adalah semua data yang diperoleh secara tidak langsung dari objek yang diteliti(Situmorang et al., 2010). Adapun data sekunder yang diambil adalah: 1)Gambaran Umum Pelabuhan Tanjung Priok, 2) Sejarah Singkat Pelabuhan Tanjung Priok, 3) Fasilitas Yang Dimiliki oleh Pelabuhan Tanjung Priok, 4) Letak Geografis Pelabuhan Tanjung Priok, 5) Gambaran Umum PT Salam Pacific Indonesia Lines Cabang Jakarta, 6) Sejarah Singkat PT Salam Pacific Indonesia Lines Cabang Jakarta, 7) Profil Perusahaan PT Salam Pacific Indonesia Lines Cabang Jakarta, 8) Fasilitas Yang Dimiliki oleh PT Salam Pacific Indonesia Lines Cabang Jakarta, 9) Struktur Organisasi PT Salam Pacific Indonesia Lines Cabang Jakarta, 10) Kegiatan di PT Salam Pacific Indonesia Lines Cabang Jakarta.

Metode pengumpulan data terbagi menjadi 4 bagian yaitu: (1) Metode Observasi (pengamatan), metode ini sebagai upaya menghimpun data dengan cara langsung mengadakan pengamatan terhadap suatu obyek sambil mencatat semua yang telah diamati sejelas-jelasnya(Hasanah, 2017). Dalam hal ini pengamatan dilakukan di Kantor PT. Salam Pacific Indonesia Lines (SPIL) Cabang Jakarta, di pelabuhan, dan instansi-instansi terkait lainnya. (2) Metode Interview atau Wawancara, metode ini dilakukan untuk mendapatkan informasi atau pendapat dengan jalan bertanya secara langsung kepada responden (diajak wawancara) secara lisan dan berhadapan muka (Rachmawati, 2007). Pada penelitian ini, peneliti menggunakan wawancara tidak terstruktur, wawancara tidak terstruktur adalah wawancara yang bebas dimana peneliti tidak menggunakan pedoman wawancara yang sudah tersusun secara sistematis dan lengkap untuk pegumpulan datanya(Astriawati, 2019). Peneliti mengadakan wawancara langsung dengan Kepala Cabang beserta Staf atau Karyawan PT. Salam Pacific Indonesia Lines (SPIL) Cabang Jakarta. (3) Metode Dokumenter, metode ini sebagai suatu upaya untuk mengumpulkan data yang kita peroleh dari data yang berkaitan dengan objek penelitian seperti data perusahaan, lembaga, dokumen kapal, dokumen yang diperlukan pada saat proses Clearance In dan Clearance Out kapal(Nilamsari, 2014). (4) Studi Pustaka, menurut Melfianora dalam Audi et al. (2021) teknik kepustakaan merupakan cara pengumpulan data bermacam-macam material yang terdapat di ruang kepustakaan, seperti koran, buku buku, majalah, naskah, dokumen dan sebagainya yang relevan dengan penelitian. 


\section{HASIL DAN PEMBAHASAN}

PT. Salam Pacific Indonesia Lines (SPIL) berpusat di Surabaya dan memiliki 18 cabang serta 4 kantor perwakilan tersebar di seluruh wilayah Indonesia, dan salah satu di antar cabang tersebut adalah di Jakarta. PT. Salam Pacific Indonesia Lines cabang Jakarta memiliki 6 lapangan penumpukan Container.

\section{Proses Clereance In}

Dalam kegiatan keagenan yang pertama kali ialah penunjukan keagenan oleh perusahaan pelayaran yaitu PT. SPIL itu sendiri dan dikarenakan PT. Salam Pacific Indonesia Lines mempunyai kapal sendiri maka jadwal untuk kapal datang dirapatkan setiap hari dan diupdate setiap harinya. Hal pertama yang dilakukan agen adalah selalu update berita kapal selama perjalanan (Branch Report) dan melakukan kontak ke pihak kapal khususnya kepada (Captain Kapal) untuk mengirimkan (Master Cable) untuk mengetahui schedule kapan kapal tiba.

Untuk proses Clearance In agen mengajukan layanan kedatangan kapal dalam waktu paling lambat 1x24 jam, terlebih dahulu agen harus mendaftarkan kapal dengan mengajukan penunjukan keagenan ke sistem (Inapornet) untuk diverifikasi oleh Penyelenggara Pelabuhan (KSOP). Kegiatan keagenan kapal yang dilakukan oleh PT. Salam Pacific Indonesia Lines menggunakan sistem-sistem seperti berikut ini: SIMLALA, SIMPONI, SIMOPEL, IDPCS, INAPORNET

\section{SIMLALA}

Sistem yang digunakan pertama adalah menggunakan Simlala untuk mengambil nomor Rencana Pola Trayek (RPT) yang digunakan oleh kapal Liner adalah surat persetujuan penempatan kapal berbendera Indonesia yang melayani trayek tetap dan teratur (liner), dalam rangka menunjang angkutan laut dalam negeri.

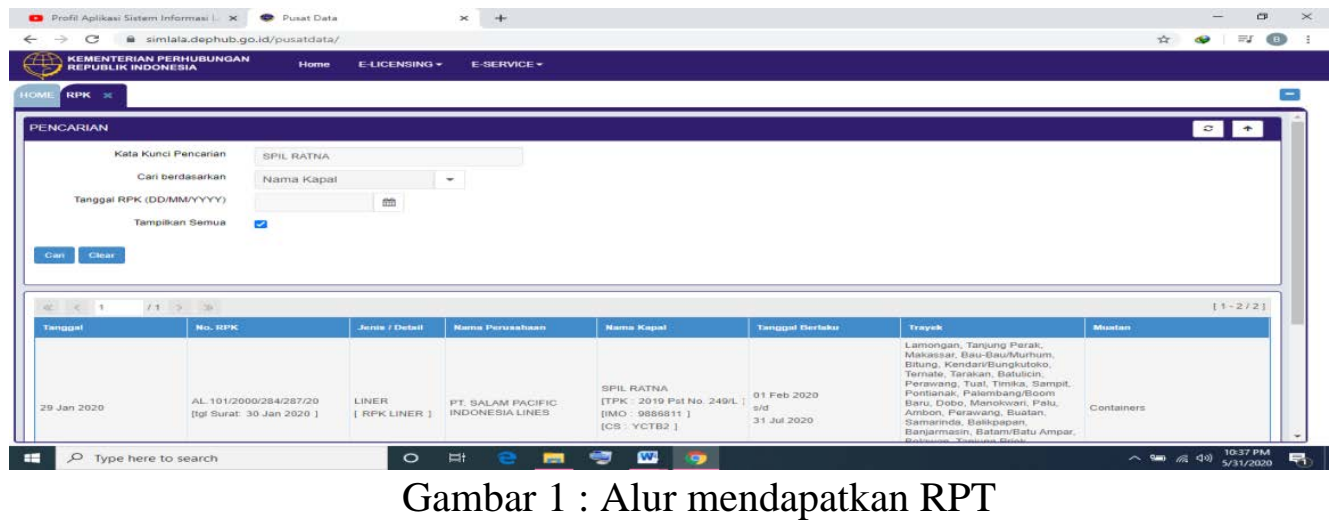

\section{INAPORNET}

Peneliti melanjutkan ke sistem inapornet untuk membuat wartakapal, di lanjutkan melengkapi data pada warta kapal tersebut dengan selengkap-lengkapnya untuk selanjutnya warta dikirimkan ke Penyelenggara Pelabuhan dalam bentuk PKK dan ke Syahbandar dalam bentuk SPM. 


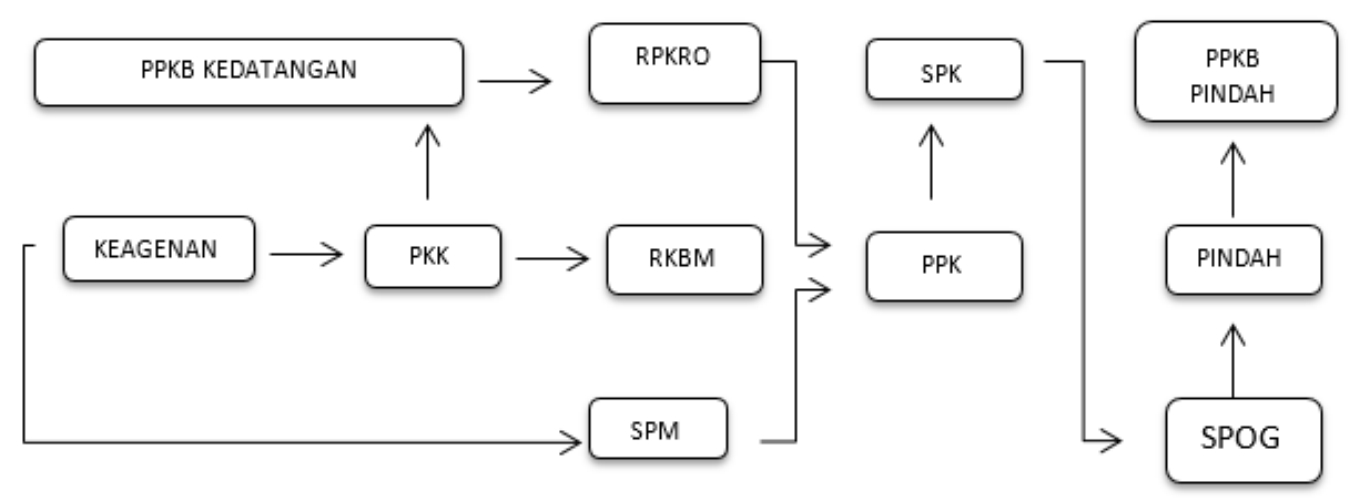

Keterangan :

Gambar 2 : Monitoring Inapornet Clearance In

PPKB : Permintaan Pelayanan Kapal dan Barang

PKK : Pemberitahuan kedatangan kapal

SPM : Surat persetujuan kapal masuk

RKBM : Rencana kegiatan bongkar muat

RPK-RO: Rencana penambatan kapal dan rencana operasi

PPK : Penetapan penambatan kapal

SPK : Surat perintah kerja

PPK : Penetapan Pelayanan Barang

SPOG : Surat persetujuan olah gerak

Dalam proses verifikasi oleh masing-masing instansi. Setelah PKK dan SPM di setujui PKK yang telah di verifikasi oleh Penyelenggara Pelabuhan yaitu Otoritas Pelabuhan.

\section{IDPCS}

Pihak agen kapal PT SPIL melakukan pemesanan pelayanan kapal (PPKB) ke PPSA yaitu untuk kapal yang berlabuh, tambat, pandu dan pelayanan jasa lainnya dengan menggunakan sistem IDPCS.

\section{SIMOPEL}

Sebuah sistem yang digunakan untuk mempermudah pengecekan pelayanan jasa yang sudah di isi didalam IDPCS. Untuk selanjutnya BUP mengirimkan data RPK-RO ke Penyelenggara Pelabuhan dari PPKB yang diajukan sebagian datanya dari PKK yang telah di verifikasi. Data yang masuk ke penyelenggara pelabuhan dalam bentuk layanan PPK untuk penyandaran kapal. Penerbitan SPK Pandu dari BUP apabila PPK telah di tetapkan oleh Penyelenggara Pelabuhan (KSOP). Setelah diverifikasi maka kapal sudah ditetapkan untuk labuh, tambat, Pandu dan juga tambat di pelabuhan Tanjung Priok. Setelah ditetapkannya kapal untuk masuk ke dermaga yang dilakukan agen kapal seperti berikut ini.

\section{Penanganan Kapal Tiba}

Setelah kapal sandar di dermaga maka pihak agen segera melakukan boarding kapal (mengambil dokumen-dokumen kapal) guna proses clearance in kapal. Pada kegiatan port clearance in, PT Salam Pacific Indonesia Lines membagi dua orang karyawannya untuk melakukan clearance ke Instansi terkait. Pada saat kapal sandar maka agen naik ketas kapal untuk mengambil dokumen-dokumen kapal seperti: 
1. Dokumen Kapal seperti: Surat Kebangsaan Kapal (Port Registry), Surat Ukur (International Tonage Certificate), Cargo Ship Construction Certificate, Cargo Ship Safety Equipment Certificate, Cargo Ship Safety Radio Certificate, Sertifikat Internasional Pencegahan Pencemaran Oleh Minyak (IOPP), International Anti Fouling Sistem Certificate, Minimum Safe Manning Certificate, Safety Management Certificate (SMC), Document Of Complaint (DOC), Port State Control (PSC), International Ship Security Certificate (ISSC), Certificate of Class, International Load Line Certificate, Last Port Clearance, Buku Kesehatan (Health Book), Derating Certificate, Certificate of Re Inspection Life Raft (ILR), Fire Extinguishing Service and Report Certificate (CO2)

2. Dokumen Awak Kapal / Crew seperti: Buku Pelaut, B.S.T Certificate (Basic Safety Training), Ijazah Profesi dan Pengukuhannya, Perjanjian Kerja Laut (PKL). Setelah diambil diatas kapal, maka dokumen-dokumen tersebut dibawa ke kantor PT. SPIL, untuk melakukan lapor tiba ke instansi terkait seperti berikut ini.

\section{Pelaksanaan Clearance ke Syahbandar}

Saat kapal berada di dermaga Pelabuhan Tanjung Priok, pihak agen dengan dokumen kapal yang diambil dari kapal segera melakukan lapor tiba ke syahbandar. Proses lapor tiba ini merupakan proses awal yang menyatakan ijin dari pihak yang berwenang di pelabuhan untuk melakukan aktivitasnya di pelabuhan Tanjung Priok. Dengan menyiapkan dokumen seperti Memorandum, Warta kapal, SPB pelabuhan asal, dan Manifest B/M. Proses Clearance yang di lakukan agen di Syahbandar. Pihak agen PT. Salam Pacific Indonesia Lines membawa dokumen yang telah disiapkan dan juga dokumen-dokumen kapal untuk diserahkan kepada syahbandar Pelabuhan Tanjung priok. Setelah diperiksa oleh pihak syahbandar dan tidak ditemukan kesalahan pada seluruh dokumen (tidak ada dokumen yang expired) maka dokumen dibawa kembali kekantor untuk disimpan sampai nanti diperlukan untuk clearance out kapal tersebut.

\section{Selama Kapal di Dermaga}

Selain melakukan kegiatan bongkar dan muat di pelabuhan, biasanya setiap kapal akan meminta pelayanan lainnya kepada agen seperti : pelayanan air tawar, logistik, bankering, crew sign off/sign on. Hampir semua kapal yang dimiliki oleh PT. Salam Pacific Indonesia Lines mengikuti seluruh panduan yang ada di dermaga dengan baik untuk mempermudah dan mempercepat kegiatan B/M yang ada dipelabuhan, sedang tugas agen memonitor jika ada yang dibutuhkan oleh kapal.

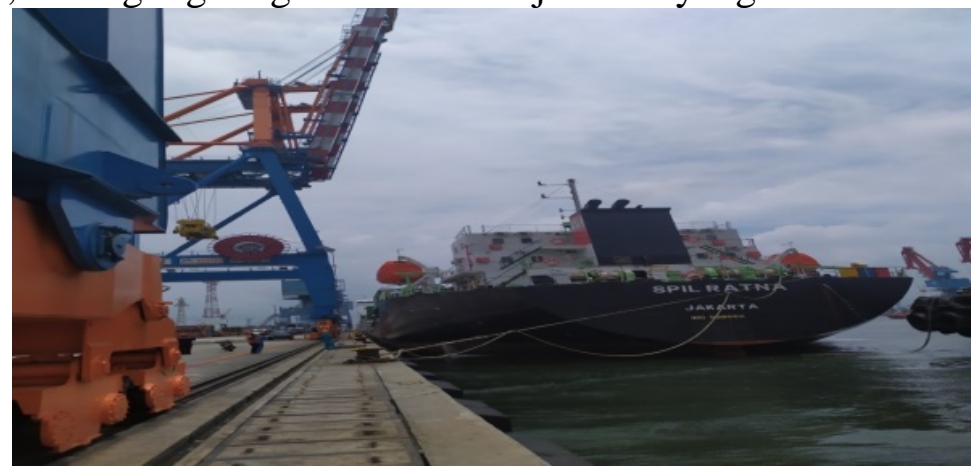

Gambar 3. Kegiatan Bongkar Muat Kapal Di Pelabuhan Tanjung Priok 


\section{Proses Clearance Out}

Setelah kapal selesai melakukan kegiatan di pelabuhan dan akan kembali lagi berlayar keluar dari wilayah pelabuhan, maka agen melakukan kembali permohonan keberangkatan kapal atau Clearance Out. Dalam waktu paling lama 4 (empat) jam sebelum kapal keluar agen mengajukan layanan kapal keluar di sistem Inaportnet yang datanya masuk ke Penyelenggara Pelabuhan (berupa LKK dan LK3, sebelumnya agen membuat warta keberangkatan yang isisnya sebagai berikut : Data Manifest Kapal Muat, Data Awak Kapal, Dokumen Kapal, Pandu Keluar.

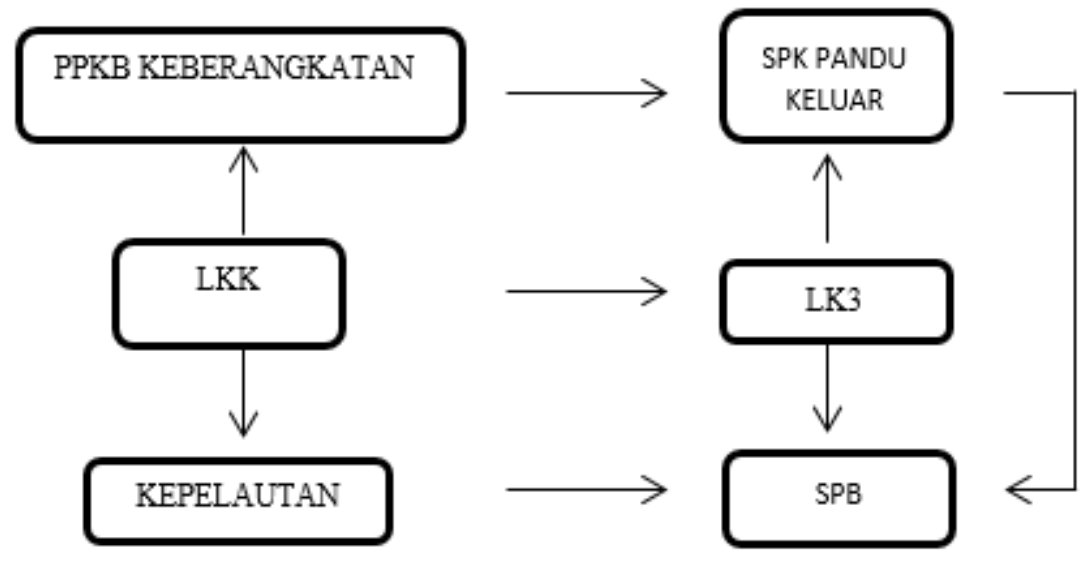

Gambar 4.Monitoring Inapornet Clearance Out

Setelah semua warta kapal di isi dengan lengkap dan benar, agen mengirimkan ke SIMLALA untuk kemudian di verifikasi apakah ada revisi atau sudah benar. LKK yang telah diverifikasi oleh penyelenggara pelabuhan akan secara otomatis direspon oleh SIMPONI untuk penerbitan kode Billing yang selanjutnya agen melakukan pembayaran PNBP Labuh dari Kode Billing yang didapat, apabila telah dilunasi oleh agen secara otomatis LK3 sudah bisa di lakukan verifikasi dan data bisa masuk ke Syahbandar sehingga bisa melakukan verifikasi data agar SPB terbit. Pihak agen menelpon ke panduan untuk menetapkan kapan pernerbitan SPK Pandu untuk kapal keluar. Dan penerbitan SPOG paling lambat 1 (satu) jam sejak SPK Pandu diterbitkan. Untuk keperluan Clearance Out di syahbandar untuk kapal PT. Salam Pacific Indonesia Lines harus melampirkan 8 dokumen, dokumen tersebut di peruntukan untuk arsip agen pelayaran seperti: Master Sailing Declaration, Rambu, VTS, Crew List, Memorandum, Manifest Muat, Surat, Warta Kapal, Safe Manning. Setelah proses Clearance SPB (Surat Persetujuan Berlayar) selesai dan semua administrasi-administrasi keperluan kapal sudah terbayarkan, agen membuat wartakapal order ke pandu labuh dan tambat untuk kepastian keberangkatan kapal setelah pandu On Board kapal Berangkat melanjutkan pelayaran ke Pelabuhan berikutnya. Surat Persetujuan Berlayar (SPB) berlaku di pelabuhan sebelum bertolak ke pelabuhan berikutnya adalah 1 kali 24 jam. 


\section{SIMPULAN}

Didalam kegiatan Clearance In dan Clearance Out kapal pihak dinas luar PT. Salam Pacific Indonesia Lines diharuskan melakukan kegiatan tepat dan cepat. Prosedur sudah dilakukan dengan baik. Semua kegiatan sudah terorganisir untuk mengurangi kesalahan saat melakukan kegiatan Clearance In dan Clearance Out kapal tersebut. Adapun prosedur clearance kapal sebagai berikut: (1) Pengurusan kedatangan kapal (Clearance In) Pihak operasional PT. Salam Pacific Indonesia Lines melakukan clearance dengan menggukaan sistem online seperti, SIMLALA, SIMOPEL, IDPCS, INAPORNET, SIMPONI. Untuk mendorong, mempercepat kegiatan-kegiatan operasional dalam mengurusi kapal sendiri, (2) Pengurusan keberangkatan kapal (Clearance Out): Pihak operasional PT. Salam Pacific Indonesia Lines memacu setiap kegiatan clearance dikarenakan setiap harinya kapal dari PT. Salam Pacific Indonesia Lines masuk dan keluar dengan cepat untuk membuat prokduktivitas dalam kegiatan pengangkutan barang berjalan dengan cepat dengan dibantunya sistem online.

\section{DAFTAR PUSTAKA}

Anita, S. L., \& Asmadewa, I. (2017). Analisis dwelling time impor pada pelabuhan tanjung priok melalui penerapan theory of constraints. Jurnal Perspektif Bea Dan Cukai, 1(1).

Arikunto, S. (2010). Metode peneltian. Jakarta: Rineka Cipta.

Astriawati, N. (2019). Perawatan Sistem Pelumasan Mesin Utama Pada Kapal Km. Mutiara Sentosa II. Jurnal Teknovasi: Jurnal Teknik Dan Inovasi, 6(1), 7480.

Audi, A., Setiyantara, Y., Astriawati, N., \& Suganjar, S. (2021). EVALUASI PELAKSANAAN INERT GAS SYSTEM (IGS) PADA KAPAL TANKER (Studi Kasus Di Kapal MT. Winson No. 5 Milik Perusahaan Winson Oil Singapore). JURNAL SAINS DAN TEKNOLOGI MARITIM, 21(2), 126-140.

Dirhamsyah, D. (2021). PENANGANAN CLEARANCE IN DAN CLEARANCE OUT KAPAL BERBENDERA ASING DENGAN SISTEM INAPORTNET PADA PT. USDASEROJA JAYA CABANG DUMAI. Wahana Inovasi: Jurnal Penelitian Dan Pengabdian Masyarakat UISU, 10(2), 254-264.

Hasanah, H. (2017). TEKNIK-TEKNIK OBSERVASI (Sebuah Alternatif Metode Pengumpulan Data Kualitatif Ilmu-ilmu Sosial). At-Taqaddum. https://doi.org/10.21580/at.v8i1.1163

Iswanto, I., \& Widyanto, H. (2019). Globalisasi Transportasi dalam Membuka Peluang Usaha Keagenan yang Didukung oleh Program Tol Laut di Indonesia. Majalah Ilmiah Bahari Jogja, 17(1), 86-95.

Nilamsari, N. (2014). Memahami studi dokumen dalam penelitian kualitatif. WACANA: Jurnal Ilmiah Ilmu Komunikasi, 13(2), 177-181.

Pattiasina, P., \& Ningrat, A. (2021). Analisis Operasional Bongkar Muat Pada PT. Pelabuhan Indonesia IV (Persero) Terminal Peti Kemas Bitung. Prosiding Seminar Nasional Sinergitas Multidisiplin Ilmu Pengetahuan Dan Teknologi, 
4, 445-455.

Rachmawati, I. N. (2007). Pengumpulan Data Dalam Penelitian Kualitatif: Wawancara. Jurnal Keperawatan Indonesia. https://doi.org/10.7454/jki.v11i1.184

Renindya, B. P. (2020). Pelayanan Keagenan Kedatangan Dan Keberangkatan Kapal Oleh Pt Salam Pacific Indonesia Lines (Spil) Jakarta Dengan Menggunakan Sistem Inaportnet. Unimar Amni.

Samekto, A. A., \& Soejanto, S. (2014). Peningkatan Kinerja Perusahaan Ekspedisi Muatan Kapal Laut Melalui Diversifikasi Usaha. Jurnal Manajemen Transportasi \& Logistik, 1(1), 1-14.

Situmorang, S. H., Muda, I., Doli, M., \& Fadli, F. S. (2010). Analisis data untuk riset manajemen dan bisnis. USUpress.

Soendari, T. (2012). Metode Penelitian Deskriptif. Bandung, UPI. Stuss, Magdalena \& Herdan, Agnieszka, 17.

Sugeng, C., \& Palippui, H. (2021). ANALISIS STRATEGI LOGISTIK (STUDI KASUS: PELAYANAN PETIKEMAS DI MAKASSAR NEW PORT). SENSISTEK: Riset Sains Dan Teknologi Kelautan, 60-66.

Suryantoro, B., Punama, D. W., \& Haqi, M. (2020). Tenaga Kerja, Peralatan Bongkar Muat Lift On/Off, Dan Efektivitas Lapangan Penumpukan Terhadap Produktivitas Bongkar Muat Peti KEMAS. Jurnal Baruna Horizon, 3(1), 156169.

Undang-Undang Republik Indonesia No. 17 Tahun 2008. (2008). Undang Undang Tahun 2008 tentang Pelayaran. Jakarta.

Wibowo, W., \& Astriawati, N. (2021). Sistem Pendingin Tertutup Pada Mesin Diesel Tipe Diesel MAK 8M32 Sebagai Penggerak Utama Kapal Motor LIT ENTERPRISE. Jurnal POLIMESIN, 19(1), 28-34.

Wijaya, A., Sisca, S., Silitonga, H. P., Candra, V., Butarbutar, M., Sinaga, O. S., Hasibuan, A., Efendi, E., Priyojadmiko, E., \& Simarmata, J. (2020). Manajemen Operasi Produksi. Yayasan Kita Menulis. 